\title{
Wolfgang Grisold, Riccardo Soffietti, Stefan Oberndorfer, Guido Cavaletti (eds): Effects of cancer treatment on the nervous system
}

\author{
Cambridge Scholars Publishing, 2020-2021, Volumes 1 and 2
}

Wolfgang Grisold ${ }^{1}$

Received: 25 February 2021 / Accepted: 1 March 2021 / Published online: 20 March 2021

(C) Fondazione Società Italiana di Neurologia 2021

The book on complications of cancer therapy has been edited by 4 experienced neuro-oncology editors: Drs. Cavaletti G, Grisold W, Oberndorfer St, and Soffietti R, and contains 35 chapters written by international authors $[1,2]$.

According to the WHO, cancer is the second leading cause of death globally, and is responsible for an estimated 9.6 million deaths in 2018 (https://www.who.int/news-room/factsheets/detail/cancer). Despite the improvement of therapies and concepts, cancer remains a serious and often fatal disease. Approximately $70 \%$ of deaths from cancer occur in low and middle income countries.

Therapies are more effective and also side effects of therapies on the nervous system occur. In addition, the classic combination of surgery, radiotherapy, chemotherapy, and hormonal therapy receives additional and new approaches as targeted therapies, immune checkpoint inhibitors, and Car T cell therapies among others. In several cancer types, therapies prolong survival and may even cure patients. Thus, a new category of cancer patients, long-term survivors, appear, which may have transient or permanent damage of the nervous system.

This 2 volume book focuses on the basic concepts of cancer, and also epidemiology in regard to neurological involvement. Measuring side effects by scales and scores is important as well as the quantification of toxic effects.

The book contains several chapters on patient issues, as the involvement in study design, care for patients and families, patient groups, palliative care, and also an analysis of the cancer situation on low and middle income countries.

Wolfgang Grisold

grisoldw@gmail.com

1 Ludwig Boltzmann Institute for Experimental und Clinical Traumatology, Donaueschingenstraße 13, A-1200 Vienna, Austria
Volume 2 focuses on the side effects of cancer therapies as surgery, chemotherapy, and radiotherapy targeted therapies, immune checkpoint inhibitors, and the armentarium of cancer therapies.

The peripheral nervous system is discussed in detail in regard to cranial nerves, nerve roots, plexus, and poly- and mononeuropathies, as well as the neuromuscular junction and muscle. The frequent and important topic of sarcopenia and cachexia closes this volume.

The book will facilitate and help in finding the accurate diagnosis in cancer patients, where neoplastic, hormonal, and infection and rarely paraneoplastic causes are often difficult to discriminate from side effects, but require an entirely different therapeutic approach.

The intention is to point out and describe not only the numerous effects on cancer therapy, and update the present knowledge on side effects, but also include general and in particular patient-related issues.

\section{Declarations}

Ethical approval None.

Conflict of interest None.

\section{References}

1. Grisold W, Soffietti R, Oberndorfer S, Cavaletti G (2020) Effects of cancer treatment on the nervous system, vol 1. Cambridge Scholars Publishing, Newcastle upon Tyne

2. Grisold W, Soffietti R, Oberndorfer S, Cavaletti G (2021) Effects of cancer treatment on the nervous system, vol 2. Cambridge Scholars Publishing, Newcastle upon Tyne

Publisher's note Springer Nature remains neutral with regard to jurisdictional claims in published maps and institutional affiliations. 